\title{
Public Awareness and Attitudes about Redistricting Institutions
}

\author{
Costas Panagopoulos ${ }^{1}$ \\ ${ }^{1}$ Department of Political Science, Fordham University, Bronx, NY, USA \\ Correspondence: Costas Panagopoulos, Department of Political Science, Fordham University, Bronx, NY, USA \\ Canada. Tel: 1-718-817-3967. E-mail: costas@post.harvard.edu
}

Received: April 13, 2013 Accepted: May 30, 2013 Online Published: August 30, 2013

doi:10.5539/jpl.v6n3p45

URL: http://dx.doi.org/10.5539/jpl.v6n3p45

\begin{abstract}
Studies demonstrate that the public is generally poorly informed about redistricting institutions. This article uses evidence from a nationally representative survey to examine levels of familiarity and satisfaction with redistricting institutions. I also investigate the popular claim that citizens will perceive greater fairness in redistricting when the process is conducted by independent, nonpartisan commissions rather than by state legislatures. Using a survey experimental approach, I show that perceptions of fairness in redistricting differ little when subjects are informed redistricting will be conducted by a nonpartisan commission compared to state legislatures.
\end{abstract}

Keywords: redistricting, public opinion, public attitudes, awareness, survey experiment

\section{Introduction}

Studies have demonstrated that, while there is considerable variation in what Americans know about politics, the public is generally poorly informed about the basic structures of many political institutions and processes (Delli Carpini \& Keeter, 1997). Citizens' knowledge about redistricting, in particular, tends to be especially low (McDonald, 2008; Tolbert, Smith \& Green, 2009; Fougere, Ansolabehere, \& Persily, 2010). In fact, Fougere, Ansolabehere and Persily (2010: 328) report that nearly three-in-five Americans do not know what body is responsible for redistricting. Awareness and opinions about redistricting can be explained partly by demographics as well as political attitudes and context (Fougere et al., 2010), but it is also likely that significant variation in legislative redistricting processes across states (McDonald, 2004) and the fact that boundaries are redrawn only decennially contribute to low levels of information about the process.

Despite low levels of awareness about the process overall, research reveals the public is generally skeptical about redistricting institutions (Fougere et al., 2010). Concerns about the potential for partisan (or other types of) gerrymandering and declining competition in elections (Cain, MacDonald \& McDonald, 2005) have inspired critics to launch aggressive campaigns for reform in recent decades. Scholarly research has provided some ammunition to these efforts partly by documenting the growth in the number of Congressional districts affected by bipartisan, incumbent-protecting gerrymanders and the corresponding effects on the number of competitive districts between the 1970s and 2000s (Cain et al., 2005). Cain et al. (2005: 22) claim that redistricting was directly responsible for 21 out of 26 districts that became less competitive (defined as having a normalized presidential vote in the 48 to 52 percentage point range) between 1990 and 2002 . The public has certainly not been entirely oblivious to these developments as survey research indicates there is widespread interest in reforming the line-drawing processes in states across the country.

While the notion of an ideal, one-size-fits-all solution to the potential for mischief in the redistricting process may be impractical, several popular reforms have been considered, and even adopted, in many jurisdictions. One popular class of reform proposals in recent cycles has been the formation of independent, nonpartisan commissions to manage the decennial redistricting process (Brunell, 2008; Mann \& Cain, 2005). Such entities could conceivably limit the role of partisans and incumbents in redistricting there by help to produce more competitive districts (Cain et al., 2005: 28). Critics contend that any such commissions could never truly be nonpartisan and that it may be naïve to expect politics to be extricated entirely from redistricting (Brunell, 2008). Thomas Mann (2005: 101) has argued that the structure of commissions is variable and that commissions usually produce redistricting plans that reflect their structure and rules. He cautions that, "[d]esigning a commission that is neutral toward or that dampens the influence of both incumbents and parties is a challenge with which few 
states have successfully grappled (2005: 101). Nevertheless, the public is generally receptive to independent commissions as an alternative to legislative districting by politicians (Fougere, 2005), and several states have embraced redistricting commissions with primary or advisory redistricting authority (McDonald, 2004).

Supporters extol independent redistricting commissions for many virtues; commonly these include the assertion that citizens would perceive the redistricting process to be conducted more fairly than if the process is managed by politicians who have a vested interest in the outcome. While this claim seems reasonable, little scholarly evidence has been put forth to suggest such a causal connection. The lack of reliable evidence on this score can be consequential and has the potential to compromise public debates about redistricting reform. This study aims to fill that void by testing this claim directly.

\section{Theoretical Expectations and Hypotheses}

This study has two main purposes. First, I aim to describe and explain levels of awareness and familiarity with redistricting processes. My second objective is to examine whether individuals perceive the redistricting process to be fairer if it is carried out by a nonpartisan commission compared to a partisan process (by the state legislature, for example). Given the claims summarized above, it is reasonable to expect that individuals would perceive a partisan process to be less fair, all else equal. But the answer may not be so simple. It is likely that perceptions of fairness are moderated by citizens' underlying levels of awareness and satisfaction with the redistricting institutions in place in their respective jurisdictions. A reasonable hypothesis is that, for citizens who report being aware of, and satisfied with, their respective redistricting institutions, the alternative may not be as attractive in terms of fairness perceptions, for example. Those who are familiar but dissatisfied with the existing redistricting institutions may be more likely to perceive greater fairness in the alternative, by contrast. Finally, I hypothesize that citizens who are unfamiliar with the redistricting institutions in place in their respective locales may, in fact, perceive nonpartisan processes to be more fair than partisan institutions. I test these hypotheses below using survey research methodology and an imbedded survey experiment. The following section described the data and methodological procedures.

\section{Methods}

First, I begin with an examination of public knowledge and attitudes about redistricting and explain these based on individuals' characteristics. To advance these analyses, I rely on survey data collected by the 2008 Cooperative Congressional Election Study (CCES). The 2008 CCES, conducted over the Internet by YouGov/Polimetrix, was a national stratified sample survey administered to 32,800 individuals in two waves. Respondents were interviewed in October 2008 for the pre-election wave and in November 2008 for a post-election wave. The CCES included common content items that were asked of all respondents. In addition, individual, participating research teams designed specific content modules asked of 1,000 respondents (Note 1).

Second, I examine whether perceptions about fairness in the redistricting process vary based on whether boundaries are perceived to be drawn by a political (by state legislatures) or an independent (by nonpartisan redistricting commissions) process. Admittedly, as I discuss above, the range of institutional forms is far more diverse, but citizens are not always attuned to these differences; the dichotomy with which respondents are presented in this study is designed to enable them to distinguish a political from an independent process more easily. As I note above, reformers have embraced initiatives designed to designate responsibility for redistricting to nonpartisan, independent commissions as a way of improving public confidence in the process, but reliable scholarly evidence that such effects would ensue is elusive. To investigate this question, I implemented a survey experiment in the 2008 CCES. Randomized experimentation has become increasingly popular in the social sciences partly by virtue of its capacity for reliable causal inference. The key manipulation in the experiment was to randomly inform subjects about the type of institution that would redraw district boundaries and to subsequently probe them about their perceptions of fairness in the process.

\section{Results: Awareness and Attitudes about Redistricting}

I begin by focusing on the public's familiarity and satisfaction with redistricting institutions. To gauge levels of these, respondents in the Fordham CCES module were asked the following question: "Are you satisfied or dissatisfied with the process by which Congressional district lines are drawn in your state?" Response options included "satisfied" or "dissatisfied" as well as a "don't know how congressional lines are drawn in my state" option.

Table 1 reports the distributions of responses to the survey item above for select subgroups of respondents. The results indicate the public is generally poorly aware of how redistricting is conducted in their respective states. Overall, a majority of respondents (54 percent) indicated they were not aware of how congressional lines are 
drawn in their states. Additionally, levels of satisfaction and dissatisfaction overall were even -at 23 percent each.

Table 1. Familiarity and satisfaction with redistricting process

\begin{tabular}{lccc}
\hline & Satisfied & Dissatisfied & Don't Know \\
\hline Overall & 23 & 23 & 54 \\
Age $<30$ & 19 & 12 & 69 \\
Age $>30$ & 24 & 27 & 49 \\
Men & 24 & 32 & 44 \\
Women & 22 & 15 & 64 \\
White & 25 & 25 & 50 \\
Black & 11 & 18 & 71 \\
Hispanic & 14 & 19 & 67 \\
Democrat & 21 & 19 & 60 \\
Republican & 33 & 24 & 43 \\
Independent & 19 & 31 & 50 \\
Commission (Actual) & 22 & 19 & 59 \\
Legislature (Actual) & 23 & 25 & 52 \\
\hline
\end{tabular}

Notes: Figures represent (mean) percentages (weighted). Question wording: Are you satisfied or dissatisfied with the process by which Congressional district lines are drawn in your state?

An initial look at the results also reveals some key differences in levels of awareness as well as satisfaction by key demographic, attitudinal and contextual characteristics. Analysis of the data using difference-of-means tests suggests blacks and Hispanics are significantly more likely (at conventional, $\mathrm{p}<.05$ level) than whites, and Democrats are significantly more likely than Republicans, to report not knowing how congressional district boundaries are drawn in their states. Older Americans are significantly less likely than younger Americans, men are significantly less likely than women, and more educated citizens are significantly less likely than less educated respondents to report not knowing how congressional boundaries are drawn in their states. Interestingly, those respondents who reside in states in which independent commissions possess the primary authority for legislative redistricting are equally as likely as their counterparts in states in which legislators conduct the process to be familiar with redistricting procedures (Note 2).

Turning next to levels of satisfaction by demographic attributes, I find that younger Americans (under 30), report being more satisfied than dissatisfied, while levels of satisfaction are more evenly distributed for Americans over 30. Men report being less satisfied overall while the reverse is true for women. Whites are evenly split in terms of satisfaction levels while blacks and Hispanics appear to be less satisfied with how redistricting is conducted. In terms of partisanship, both Democrats and Republicans are more satisfied than dissatisfied, although net levels of satisfaction are greater for Republicans than Democrats. Independents are much less satisfied with redistricting procedures.

For a more rigorous analysis, I employ multiple regression (probit) to explain levels of satisfaction with and awareness of redistricting procedures. I estimate two models separately. Model 1 (Table 2, column 1) explains satisfaction with redistricting (given respondents indicated they were familiar with redistricting institutions) and Model 2 (Table 2, column 2) explains lack of familiarity with redistricting institutions as a function of respondents' demographic traits (age, gender, race, income and education), political attitudes (partisan identification) and contextual characteristics (in this case, whether or not the respondent resides in a state in which redistricting is conducted mainly by an independent commission). The dependent variable in Model 1 is coded 1 if the respondent expressed being satisfied with the process by which Congressional district lines are drawn in their state, 0 if they were dissatisfied ("Don't Know" responses excluded); In Model 2, the dependent variable is coded 1 if respondent indicated they did not know how Congressional district lines are drawn in their state, 0 otherwise. Indicator (dummy) variables are used to denote gender (male $=1$, female $=0)$, race (white $=1,0$ 
otherwise), partisanship (Democrat=1, Republican=2, Independent=3) as well as whether or not the respondent lives in a state in which a commission has the primary authority to conduct redistricting (commission=1, 0 otherwise); ordinal scales are used for income and education.

Table 2. Familiarity and satisfaction with redistricting process

\begin{tabular}{|c|c|c|}
\hline & Satisfaction (1) & Familiarity (2) \\
\hline \multicolumn{3}{|l|}{ Independent Variables } \\
\hline \multirow[t]{2}{*}{ Age } & -.005 & $-.013 * * *$ \\
\hline & $(.004)$ & $(.004)$ \\
\hline \multirow[t]{2}{*}{ Male } & $-.338^{* *}$ & $-.468 * * *$ \\
\hline & $(.149)$ & $(.116)$ \\
\hline \multirow[t]{2}{*}{ White } & -.004 & $-.319 * *$ \\
\hline & $(.201)$ & $(.150)$ \\
\hline \multirow[t]{2}{*}{ Income } & .020 & $-.032 *$ \\
\hline & $(.024)$ & $(.018)$ \\
\hline \multirow[t]{2}{*}{ Education } & -.024 & $-.091 * *$ \\
\hline & $(.052)$ & $(.040)$ \\
\hline \multirow[t]{2}{*}{ Democrat } & $.385^{* *}$ & .041 \\
\hline & $(.190)$ & $(.148)$ \\
\hline \multirow[t]{2}{*}{ Republican } & $.561 * * *$ & -.193 \\
\hline & $(.184)$ & $(.149)$ \\
\hline \multirow[t]{2}{*}{ Redistricting Commission (Actual) } & .144 & .205 \\
\hline & $(.161)$ & $(.132)$ \\
\hline \multirow[t]{2}{*}{ Constant } & -.003 & $1.659 * * *$ \\
\hline & $(.347)$ & $(.281)$ \\
\hline$N$ & 451 & 828 \\
\hline Log Likelihood & -241.080 & -479.172 \\
\hline Pseudo $\mathrm{R}^{2}$ & .04 & .10 \\
\hline
\end{tabular}

Notes: Probit regression (weighted). Model 1 (column 1): Dependent variable is coded 1 if respondent expressed being satisfied with the process by which Congressional district lines are drawn in their state, 0 if they were dissatisfied ("Don't Know" responses excluded); Model 2 (column 2) Dependent variable is coded 1 if respondent indicated they do not know how Congressional district lines are drawn in their state, 0 otherwise. Robust standard errors in parentheses. $* * *$ indicates statistical significance at the $\mathrm{p}<.01$ level, ** at the $\mathrm{p}<.05$ level, and * at the $\mathrm{p}<.10$ level, using two-tailed tests.

The results of the estimations are presented in Table 2 (Note 3). The evidence reveals that, all else equal, men were significantly less likely to be satisfied with redistricting procedures, compared to women. Partisans (both Democrats and Republicans) were also significantly more likely to express satisfaction with redistricting 
compared to Independents. No other differences were statistically significant. An especially intriguing finding is that those respondents who reside in states in which commissions are primarily responsible for redistricting were no more likely than citizens living in states where legislators manage the process to express greater satisfaction given they expressed an opinion about redistricting.

With respect to awareness about redistricting institutions, younger respondents were significantly less likely than older respondents to indicate they were familiar with redistricting procedures in their respective states, all else equal. Men were also more likely to express familiarity with redistricting procedures compared to women. Higher income and education levels were also significantly associated with higher levels of awareness about redistricting institutions as was being white (compared to minorities). I find no statistically significant differences in self-reported awareness about redistricting by partisanship or by the type of redistricting institution actually in place in respondents' respective states, all else equal.

Taken as a whole, the results I describe above reinforce findings from previous studies (Fougere et al., 2010) that demonstrate there are significant differences with respect to both satisfaction with and awareness about redistricting institutions rooted in key sociopolitical and demographic characteristics. That said, there are some differences across studies with respect to the influence of some characteristics on levels of redistricting satisfaction and familiarity, suggesting the need for further scrutiny and additional inquiry.

\section{Results: Perceptions of Fairness and Redistricting Institutions: Experimental Evidence}

I turn next to focus on the impact of two different types of redistricting institutions (in this case, redistricting done by state legislatures compared to nonpartisan commissions) on confidence that district boundaries would be drawn fairly. Independent, nonpartisan redistricting bodies have been proposed or adopted in many states as a remedy for potential gerrymandering (McDonald 2004), and survey data suggest the public generally prefers independent redistricting commissions to districting by state legislatures (Fougere et al., 2010). Proponents argue that the adoption of such reforms would improve public perceptions of fairness in the redistricting process, but this argument has attracted little scholarly attention or scrutiny.

To investigate this claim empirically, I imbedded a randomized experiment in the Fordham module of the 2008 CCES survey. The experimental design I adopt avoids concerns about causality typically associated with observational approaches. In the real world, we cannot randomly assign citizens to jurisdictions where redistricting is conducted by the state legislature or by a nonpartisan commission, but we can attempt to manipulate such a scenario experimentally in a controlled study. Accordingly, the survey experiment included two experimental conditions. Half of respondents were assigned randomly to be asked the following question: "As you may know, the next census in the U.S. will be conducted in 2010, and the congressional district boundaries in your district may be redrawn. How confident are you that the state legislature will redraw congressional district boundaries fairly?" The other half of respondents were asked the identical question, but the words "state legislature" were replaced with "nonpartisan commission appointed." This was the key manipulation in the survey experiment. Response categories were "very confident," "fairly confident," "not too confident" or "not at all confident."

Given random assignment to each experimental condition, the experimental groups were, as expected, balanced with respect to observable, demographic (age, race, gender, income, education) and political traits (partisanship) as well as contextual factors (residence in states in which commissions conduct redistricting; see above). An $F$-test of the significance indicates these covariates are unrelated to assignment to experimental conditions $(F(8,816)=1.34, \mathrm{p}=.22)$, thereby confirming balance (Note 4$)$.

Table 3. Confidence district boundaries would be drawn fairly by experimental condition

\begin{tabular}{ccc}
\hline & State Legislature & Independent Commission \\
\hline Very Confident & 5 & 5 \\
Fairly Confident & 47 & 36 \\
Confident & $\mathbf{5 2}$ & $\mathbf{4 1}$ \\
Not too Confident & 36 & 40 \\
Not at all Confident & 12 & 19 \\
Not Confident & $\mathbf{4 8}$ & $\mathbf{5 9}$ \\
\hline
\end{tabular}

Note: Figures represent (mean) percentages (weighted). 
The response distributions for each experimental condition are reported in Table 3. Overall, the results suggest that at least half of respondents failed to express confidence that the redistricting process yields boundaries that are drawn fairly regardless of which experimental condition respondents have been assigned to. This finding is consistent with majorities of survey respondents in previous studies who believed redistricting was not conducted fairly (Fougere et al., 2010). Furthermore, initial analysis of the experimental results shows that respondents who were told their congressional district boundaries would be drawn by the state legislature were actually more likely than subjects who were told lines would be drawn by a nonpartisan commission to express greater confidence that lines would be drawn fairly. We explore this further in the analyses below.

Survey Experiment Question wording: As you may know, the next census in the U.S. will be conducted in 2010, and the congressional district boundaries in your district may be redrawn. How confident are you that the [state legislature/nonpartisan commission appointed] will redraw congressional district boundaries fairly?

I proceed to subject the experimental data to more rigorous empirical analysis using multiple regression (OLS) to control for random imbalance across experimental conditions (Note 5). For simplicity and ease of interpretation, I combine responses to express confidence (or not) dichotomously (Note 6). The estimates of the effects of being assigned to the redistricting commission treatment condition are presented in Table 4 both with and without the inclusion of covariates in the models (Note 7). The inclusion of covariates is optional but may improve the precision with which treatment effects are estimated by correcting for imbalances between experimental groups due to chance.

The evidence suggests those subjects who were told their congressional district boundaries would be drawn by a nonpartisan redistricting commission were significantly less likely than subjects told boundaries would be drawn by the state legislature to express confidence that lines would be drawn fairly. On average, the estimates in Table 4, column 1, indicate that confidence that district lines would be drawn fairly was more than five percentage points lower on average for subjects who were told boundaries would be drawn by a nonpartisan commission compared to those who were told boundaries would be drawn by the state legislature. This treatment effect persists even after covariates are included, as expected, but it is only statistically significant at borderline $(\mathrm{p}<.10)$ levels. Below we investigate the robustness and pervasiveness of this effect.

Table 4. Impact of being informed district boundaries drawn by nonpartisan commission on perceptions of fairness: experimental results

\begin{tabular}{ccc}
\hline & Confident District Boundaries Would Be Drawn Fairly \\
\hline Independent Commission & $-.052^{*}$ & $-.057^{*}$ \\
[Treatment $]$ & $(.032)$ & $(.034)$ \\
Covariates $^{\mathrm{a}}$ & $\mathrm{NO}$ & YES \\
$N$ & 964 & 825 \\
RMSE & .499 & .487 \\
\hline
\end{tabular}

Notes: OLS regression (weighted). Dependent variable is coded 1 if respondent expressed being "very" or "somewhat" confident that district boundaries would be drawn fairly, 0 otherwise. Standard errors in parentheses. * indicates statistical significance at the $\mathrm{p}<.10$ level, using two-tailed tests.

${ }^{a}$ Covariates include: age, gender, race, education, income, party ID, redistricting institution (actual).

How robust or pervasive is the overall negative effect that emerges? It is worth considering whether the overall, average treatment effect detected above is homogeneous or if the effects differ across various dimensions including demographic and political traits, levels of knowledge or attitudes about redistricting about which respondents were probed, or by the type of redistricting institution actually in place in subjects' home states. The average effect reported above may mask such crucial differences. To examine these questions, Table 5 presents the impact of being assigned to the nonpartisan commission treatment condition on confidence that district boundaries would be drawn fairly separately for subgroups of subjects based on a wide range of characteristics. For the most part, the results indicate assignment to the nonpartisan commission condition did little to influence perceptions of fairness in the redistricting process. In terms of demographics, only blacks and low-education respondents (high school degree or less) assigned to the nonpartisan commission condition express less confidence that lines would be drawn fairly. For other types of citizens, perceptions of fairness did not differ if 
they were told redistricting would be advanced by a nonpartisan commission.

Table 5. Impact of being informed district boundaries drawn by nonpartisan commission on perceptions of fairness by select characteristics

\begin{tabular}{|c|c|c|c|}
\hline & $\begin{array}{c}\text { Confident District } \\
\text { Boundaries Would Be } \\
\text { Drawn Fairly }\end{array}$ & $N$ & RMSE \\
\hline Under 30 & $-.006(.074)$ & 171 & .481 \\
\hline $30+$ & $-.057(.035)$ & 793 & .497 \\
\hline Men & $-.050(.045)$ & 474 & .494 \\
\hline Women & $-.064(.045)$ & 490 & .499 \\
\hline White & $-.035(.036)$ & 779 & .500 \\
\hline Black & $-.220(.120)^{*}$ & 70 & .493 \\
\hline Hispanic & $-.129(.126)$ & 64 & .473 \\
\hline Democrat & $-.041(.055)$ & 332 & .500 \\
\hline Republican & $-.048(.055)$ & 332 & .501 \\
\hline Independent & $-.020(.064)$ & 233 & .491 \\
\hline $\begin{array}{l}\text { High School Graduate } \\
\text { (or less) }\end{array}$ & $-.095(.053)^{*}$ & 358 & .499 \\
\hline Some college & $-.028(.041)$ & 606 & .499 \\
\hline Less than $\$ 50,000$ & $-.052(.051)$ & 38 & .500 \\
\hline$\$ 50,000$ (or more) & $-.051(.041)$ & 584 & .498 \\
\hline $\begin{array}{l}\text { Satisfied with } \\
\text { Redistricting }\end{array}$ & $-.097(.054)^{*}$ & 267 & .443 \\
\hline $\begin{array}{l}\text { Dissatisfied with } \\
\text { Redistricting }\end{array}$ & $.014(.046)$ & 254 & .369 \\
\hline $\begin{array}{l}\text { Don't Know How } \\
\text { Districts Drawn }\end{array}$ & $-.018(.048)$ & 438 & .501 \\
\hline $\begin{array}{l}\text { Redistricting by } \\
\text { Commission (Actual) }\end{array}$ & $.020(.064)$ & 247 & .502 \\
\hline $\begin{array}{l}\text { Redistricting by } \\
\text { Legislature (Actual) }\end{array}$ & $-.077(.037)^{* *}$ & 717 & .499 \\
\hline
\end{tabular}

Notes: OLS regression (unweighted). Dependent variable is coded 1 if respondent expressed being either "very" or "somewhat" confident that district boundaries would be drawn fairly, 0 otherwise. Standard errors in parentheses. ${ }^{* *}$ indicates statistical significance at the $\mathrm{p}<.05$ level, and ${ }^{*}$ at the $\mathrm{p}<.10$ level, using two-tailed tests. (Details available upon request.)

I also examined the effects of being assigned to the nonpartisan commission by subjects' responses to the earlier survey item probing them about their levels of awareness or satisfaction with the redistricting process. For those respondents who indicated they were satisfied with how district boundaries were drawn, they perceived the process to be less fair when conducted by a nonpartisan commission. Those who were dissatisfied with redistricting procedures or who initially indicated they were unaware of how district boundaries were drawn expressed no greater confidence in a political process compared to redistricting conducted by a nonpartisan commission.

Finally, I examine whether the impact of being informed that redistricting would be conducted by a nonpartisan commission differed by whether redistricting was actually conducted by commission rather than by the legislatures in subjects' home states. The estimated treatment effects reported in Table 5 indicate that the effect of 
being told redistricting would be conducted by a nonpartisan commission did not significantly affect perceptions of fairness in the process among subjects who resided in states in which redistricting is actually conducted by independent commissions. This is somewhat intuitive given that the nonpartisan commission treatment was simply reinforcing actual redistricting procedures in place for these subjects. By contrast, subjects residing in states in which legislatures are responsible for redistricting were significantly less likely to perceive the process to be fair when informed it would be conducted by a nonpartisan commission compared to the state legislature. These results are intriguing because they suggest, among other things, that citizens (at least those residing in states in which redistricting is managed by politicians) may have become conditioned to perceiving redistricting institutions currently in place in their political environments to be superior in terms of fairness. In some ways, it is difficult to reconcile this finding with survey evidence that suggests citizens are suspicious of the redistricting procedures in place in their respective political contexts.

Table 6. Impact of being informed district boundaries drawn by nonpartisan commission on perception of fairness: experimental results (by awareness and satisfaction level and actual redistricting institutions)

\section{Confident District Boundaries Would Be Drawn Fairly}

\begin{tabular}{ccccccc}
\hline & Satisfied & & & Dissatisfied & & Don't Know \\
ALL & Commission & Legislature & ALL & Commission & Legislature & ALL \\
& (Actual) & (Actual) & & (Actual) & (Actual) & \\
\hline
\end{tabular}

\begin{tabular}{|c|c|c|c|c|c|c|c|c|c|c|c|c|c|c|}
\hline Nonpartisan & & & & & & & & & & & & & & \\
\hline Commission & $-.097 *$ & $-.147 * * *$ & -.106 & -.102 & -.099 & $-.176^{* *}$ & .014 & -.004 & .000 & .029 & .019 & .002 & -.018 & .024 \\
\hline$[$ Treatment $]$ & $(.054)$ & $(.055)$ & $(.100)$ & (.115) & $(.065)$ & $(.067)$ & $(.046)$ & $(.049)$ & $(.104)$ & $(.104)$ & $(.052)$ & $(.058)$ & $(.048)$ & $(.052)$ \\
\hline Covariates $^{\mathrm{a}}$ & NO & YES & $\mathrm{NO}$ & YES & $\mathrm{NO}$ & YES & NO & YES & $\mathrm{NO}$ & YES & NO & YES & NO & YES \\
\hline$N$ & 267 & 232 & 73 & 63 & 194 & 169 & 254 & 218 & 56 & 49 & 198 & 169 & 438 & 371 \\
\hline RMSE & .443 & .418 & .425 & .426 & .450 & .423 & .369 & .363 & .417 & .320 & .365 & .375 & .501 & .490 \\
\hline
\end{tabular}

Notes: OLS regression (unweighted). Dependent variable is coded 1 if respondent expressed being "very" or "somewhat" confident that district boundaries would be drawn fairly, 0 otherwise. Standard error in parentheses. *** indicates statistical significance at the $\mathrm{p}<.01$ level, $* *$ at the $\mathrm{p}<.05$ level, and * at the $\mathrm{p}<.10$ level, using two-wailed tests.

${ }^{a}$ Covariates include: age, gender, race, education, income, party ID.

The heterogeneity suggested by these results implies the impact of being informed nonpartisan, compared to political, institutions are responsible to advance redistricting is not uniform. Despite limited sample sizes, the overall, negative treatment effect presented in Table 4 is not homogeneous. Accordingly, it is worth probing further the factors that could be driving this experimental result. Table 6 advances a series of analyses along these lines. I note that roughly half of the overall sample reports familiarity with the redistricting institutions in their states; further, I acknowledge that the experimental design I adopt would have assigned some respondents at random to be informed that redistricting would be conducted by the state legislature when, in actuality, the process would have been conducted by a nonpartisan commission and vice versa. Thus, the experimental manipulation may have been inconsistent with the institutions actually in place in subjects' respective states. For subjects who indicated they were unfamiliar with redistricting institutions in their states, this would presumably not matter much. For others, however, any such inconsistency may have influenced subjects' reactions. Moreover, any such discrepancies could have biased the overall results of the experiment given that most ( 75 percent) of the respondents reside in states in which redistricting institutions are primarily political. To take this into account, the impact of assignment to the nonpartisan commission treatment is estimated separately by subjects' initial levels of awareness or satisfaction with redistricting procedures in their states as well as by whether the process is actually performed by the political (legislative) or nonpartisan process in respondents' states respectively. The 
results, reported in Table 6, are quite telling; the estimates indicate that the overall negative treatment effect is likely being driven by those respondents who are generally satisfied with redistricting procedures and who reside in states in which legislatures are responsible for drawing district boundaries. It is reasonable to observe that, for these subjects, perceptions of fairness in redistricting would be significantly diminished when informed boundaries are drawn by an alternative, nonpartisan process; after all, they report being satisfied with the political process actually in place in their states. This finding is not only intuitive but it appears to be potent enough to be driving the overall negative effect observed above and could potentially result in a misleading interpretation of the overall experimental results. For subjects who were dissatisfied with their redistricting institutions, there are no significant differences in perceptions of fairness in the redistricting process when informed a nonpartisan commission would be responsible regardless of whether a political or nonpartisan process is actually in place in their respective states. This finding may suggest that some subjects may simply be predisposed to be equally disillusioned or skeptical about redistricting regardless of whether the institutions are political or independent. Similarly, for subjects who were unaware of how district lines are drawn in their states, being informed redistricting is conducted by nonpartisan commissions resulted in no greater perception of fairness in the process compared to uninformed subjects who were told redistricting would be conducted by state legislatures.

For advocates of nonpartisan redistricting commissions, these findings may be comforting. It is worth noting, however, that the current study uncovers little evidence to support the claim that the public perceives there to be greater fairness in the redistricting process when it is conducted by an independent process compared to a political process. Thus, it is doubtful that the adoption of nonpartisan redistricting commissions would do much to enhance perceptions that the process is fair. Leaving aside the statistical uncertainties (standard errors) associated with the estimated treatment effects for subgroups of subjects reported in Table 5, nearly all of the coefficients are negative, suggesting that perceptions of fairness may actually be depressed when subjects are told redistricting will be conducted by a nonpartisan commission. This intriguing possibility begs further exploration using much larger samples.

\section{Discussion}

The findings I report above suggest the public overall remains generally poorly informed about redistricting institutions in their states. These results are consistent with previous studies that have found similarly low levels of awareness about redistricting institutions. I also show there are important differences in levels of awareness about the redistricting process across key demographic characteristics. Similarly, there are key differences in satisfaction levels about the process across key demographic characteristics among citizens who report being informed about the redistricting processes in their states,

The analyses I describe above also imply that the expectation that the public would perceive district boundaries to be drawn more fairly if drawn by a nonpartisan commission, rather than if redistricting is done by the state legislature, may be unfounded. The experimental results reported in this study suggest public perceptions of fairness in redistricting would differ little regardless of whether district lines are drawn by nonpartisan commissions or state legislatures. Thus, reforms enacted to designate redistricting to independent, nonpartisan commissions may do little to improve public perceptions of fairness in redistricting; in fact, such changes may actually erode public confidence that boundaries are drawn fairly, especially for certain groups of citizens including blacks or those with low educational attainment.

My goal in this article is not to disparage efforts to promote reforms that attempt to limit the potential for partisan or political gerrymandering. To the contrary, there may be several good reasons to consider ways to make redistricting processes and institutions less political in nature. I caution, however, that the assertion that taking redistricting out of the hands of legislators and placing it under the control of independent commissions would enhance public perceptions of fairness may need to be tempered. Rigorous, empirical scrutiny may not reveal strong support for claims along these lines. While I find little evidence of such an effect, subsequent research could investigate further if there are certain conditions under which such effects would arise.

\section{References}

Ansolabehere, S. (2009). Cooperative Congressional Election Study 2008: Common Content. [Computer File] Release 1: February 2009. Cambridge, MA: M.I.T.

Brunelle, T. (2008). Redistricting and Representation: Why Competitive Elections are Bad for America. New York: Routledge.

Cain, B., MacDonald, K., \& McDonald, M. (2005). From Equality to Fairness: The Path of Political Reform 
since Baker v. Carr. In T. Mann, \& B. Cain (Eds.), Party Lines: Competition, Partisanship and Congressional Redistricting. Washington, DC: Brookings Institution Press.

Carpini, D., Michael, \& Keeter, S. (1997). What Americans Know about Politics and Why It Matters. New Haven: Yale University Press.

Fougere, J., Ansolabehere, S., \& Nathaniel, P. (2010). Partisanship, Public Opinion, and Redistricting. Election Law Journal, 9(4), 325-347.

Mann, T. (2005). Redistricting Reform: What Is Desirable? Possible? In T. Mann, \& B. Cain (Eds.), Party Lines: Competition, Partisanship and Congressional Redistricting. Washington, DC: Brookings Institution Press.

Mann, T., \& Cain, B. (Eds.). (2005). Party Lines: Competition, Partisanship and Congressional Redistricting. Washington, DC: Brookings Institution Press.

McDonald, M. (2008). Legislative Redistricting. In B. E. Cain (Ed.), Democracy in the States: Experiments in Election Reform. Washington, DC: Brookings Institution Press.

McDonald, M. (2004). A Comparative Analysis of Redistricting Institutions in the United States, 2001-02. State Politics and Policy Quarterly, 4(4), 371-395.

Tolbert, C. J., Smith, D., \& Green, J. C. (2009). Strategic Voting and Legislative Redistricting Reform: District and Statewide Representational Winners and Losers. Political Research Quarterly, 62(1), 92-109. http://dx.doi.org/10.1177/1065912908314201

\section{Notes}

Note 1. Details about the 2008 CCES survey methodology are available at http://projects.iq.harvard.edu/cces/book/study-design.

Note 2 . At the time the survey was conducted in 2008 , independent commissions retained the primary authority to conduct redistricting in twelve states including: Alaska, Arizona, Arkansas, Colorado, Hawaii, Idaho, Missouri, Montana, New Jersey, Ohio, Pennsylvania, and Washington. Source: http://www.ncsl.org/legislatures-elections/redist/2009-redistricting-commissions-table.aspx. I acknowledge this classification scheme is rather blunt given the considerable diversity that exists across states in terms of the type of commissions in place (nonpartisan or independent, partisan, etc.), however citizens are often unaware of these nuances. For simplicity, the current study attempts to distinguish mainly between a process that is purely political (state legislatures explicitly and exclusively manage redistricting) and one that is presumably more independent (commissions).

Note 3. These analyses are weighted to be representative of the national adult population.

Note 4. Details available upon request.

Note 5. Given the dependent variable is binary, logistic or probit regression could have also been used to analyze the data. OLS is used for ease of interpretation of the estimated effects. The results are substantively similar using either logit or probit; available upon request.

Note 6. Responses are combined to be coded 1 if respondent expressed being "very" or "somewhat" confident that district boundaries would be drawn fairly, 0 otherwise.

Note 7. Given the experimental design, results reported are unweighted.

\section{Copyrights}

Copyright for this article is retained by the author(s), with first publication rights granted to the journal.

This is an open-access article distributed under the terms and conditions of the Creative Commons Attribution license (http://creativecommons.org/licenses/by/3.0/). 